\title{
Making Sense of the Cultural Other in the Fabric of Knowledge Vis-à-vis The Yoruba Cultural Framework
}

\author{
Olajiga Isaac Oladeji Ph.D \\ Depertment of Philosophy, Ekiti State University \\ Ado-Ekiti \\ olajigaisaac@gmail.com
}

\begin{abstract}
The paper recognizes openness to the cultural other in accounting for knowledge. In that acknowledgment, it rejects the ultimacy of the familiar foundationalist categories. By so doing, it adds a layer of critique to these categories, thereby encouraging an appreciation of the cultural other

The paper selects its focus on the Yoruba as a shared example of a cultural order in accounting for knowledge. It thus, gets illuminated by a distinction between knowledge (imo) and belief (igbagbo), on the one hand, and the paradox of average conception of knowing requiring consultation through Ifa, on the other hand. If a claim were to culturally count as either knowledge or belief, the paper identifies certain conditions that would culturally count for or against it, and anyone defending the claim must be prepared to evaluate it based on explanation (alaaye).

One aspect, however, requiring particular mention is that the Yoruba account has its widest appeal in that which unites the individual with the Omniscient, a unity which makes prior epistemic achievements more secured. The Yoruba recognizes Iwa (character or essence) to facilitate such understanding.
\end{abstract}

Key words: Cultural Other, Average, Knowledge, Belief, and the Yoruba.

\section{Introduction}

Philosophy recognizes diverse way of responding to the failure of universality of involvements put forth as basis for a critique of knowing. This much has stimulated critical thought in every direction. Precisely, the point at issue, consists in determining whether a universal paradigm of knowing can become the standard for others. The view, however, that so much depends on universality is faced with problems. This has resulted in an ever increasing dissipation on pseudo- problems, such as skepticism, certainty detachment, etc., hence, exhibiting the problem of universality in its full force is to exhibit its pursuit as a pseudoproblem.

This paper is focused on the close connection between the very condition of knowledge that are already in place, un-problematically, prior to the challenge of universality, within a specified culture, the Yoruba, and knowing, as a more explicit rendering. Relying on this outcome, the paper considers a rejection of all foundational categories of knowledge, and in case of any reference to them, the aim is not similar.

The paper draws upon the basic proposition and underpinnings of the category of "cultural other" as the "'known unknown', a further step beyond the "universal known'. The paper discusses the pertinent categories developed by the Yoruba as paradigmatic of a 
cultural other by attempting a critical comparison of knowledge/belief-formation in everyday involvements and one mode of knowing requiring consultation which has brought to light the priority of average conception. The thirst for knowledge, however, is not predicated on the defective acquaintance with what sense-impressions or testimonial knowledge has brought, hence, the need for Ifa, the consultant, represented by his priest. Despite the presumptive status of culture as providing conditions for knowing, the paper recognizes a generality problem in the Yoruba account. The everyday clarifications of the knowledge/belief distinction reconstitutes knowing as an elusive target to the point that we should either count or not count on its outcome, as the notion of consultancy is connected with the Yoruba epistemic practice. To understand this point, one must keep in mind that determining the nature of knowledge/belief distinction is half of the generality problem. In any case, there is still a lot to be learnt from the layer of everydayness. Kola Abimbola, admirably noted this point: "A religious culture such as Yoruba needs believers; it needs humans who organize, regulate, and conduct their day-to-day lives in terms of a world-view."1

\section{Cultural Other as a Scope That Counts}

The overall aim of defending an account of knowledge in support of the cultural other takes off by disqualifying the effects which we ordinarily attribute to a rational induced hegemony in the course of developing an account of knowledge which has been founded upon it. We have often take notice in the works of the traditional epistemologists such as Descartes, Hume, Locke and Berkeley the hegemonic rootedness in their views of knowledge while trying to retain an element of certainty as an ideal of knowledge. Certainty as an ideal of knowledge does not address itself to a multivalent ways of knowing but rather maintains that the essence and the destiny of knowledge is tied to a single source of knowing, perhaps, outside itself. Knowledge could be understood from the abstract without our being involved.

The fact of knowledge is grasped from the perspective of participating in a standard outside itself. In this sense, according to Gilles Deleuze, "I affirm more than I know; my judgment goes beyond the idea. In other words, I am a subject." 2 It is incomprehensible how human beings can meet this ideal of knowledge without a price since it ties together its notioning that the self cannot be reconciled with the others except with qualifications. This understanding for the most part has engaged foundationalist epistemology where a belief is justified only to the extent to which it is justified by a basic belief which in itself cannot be justified by another belief. The recurring undercurrent from the foundationalist category is thematic when a formula for the activity of knowing is based upon imitation or semblance. Deleuze puts the argument very succintly: "Hume suggests that, in knowledge, either we move from known to unknown circumstances, or we proceed from known to unknown relations." 3 This is what Gavin Sanderson describes as "the realm of the known unknown."

The cultural other represents a shift of focus from how something is known rationally to how it is known by others. We avoid the use of 'the rest of us' in order to avoid further appeal to foundationalism. Our understanding that knowledge can be retrieved from the forgotten layers of human existence, that is, the "known unknown" demands that more attention should be paid to the cultural other. 
The chief test of the thesis of the cultural other lies however not in its resistance to rationalism, but its power to derive outcomes by doing justice to the multiplicity of human experience which has been forgotten, taking recourse to Heidegger in the tradition where the subject that knows at the same time creates its own knowledge. The subject is partly individual and partially collective.

The supreme benefit of admitting the existential import of the cultural other lies in its utility against the conceptual difficulty of a general view of knowledge, which must be satisfied in some ways. We no longer think of truth, belief, justification, knowing, human knower, etc., as one-sidedly rational. In focusing on the cultural other, we gain an insight into rationalism with its emphasis on certainty and its consequent hostility to multiple truths, as an expression of just one source of the multiplicity of the everydayness or human experience.

There is little to be gained, however, from calling certain basic concepts in our existential profile rational. These include: truth, belief, justification, knowing, human knower and the like. This would imply that anything that is not derived from rationality is an invocation from false experience. The rational engagement with the "known unknown" is insufficiently developed to enable a cultural point of view. For Sanderson, it is unfinished business. ${ }^{5}$ For Kierkegaard, the basic concepts for the human subject cannot be reduced as essentially rational. For him, whilst it may be true that the rational absurdity of existentialist belief is indeed a benefit for existence, rational thinking makes it more difficult to believe, and so requires us to believe with a passionate intensity or patronage. The Kierkegaardian understanding of passional commitment proved itself as a challenge to Sartre, an existentialist. The focus of his, Problem of Method is to imagine the possibility of an existentialist as one who has passional commitment, to the extent of becoming a hallmark of a person giving testimony on existence.

Sartre clarifies, and in so doing, emphasises:

In fact, the subjective life, just insofar as it is lived, can never be made the object of knowledge. In principle it escapes knowing, and the relation of the believer to transcendence can only be conceived of in a form of going beyond. This inwardness, which in its narrowness and its infinite depth claims to affirm itself against all philosophy, this subjectivity rediscovered beyond language as the personal adventure of each man in the face of others and of God ... is what Kierkegaard called existence. ${ }^{6}$

This view, as it were, broadly subjective is flavoured with an existentialist sense of a human experience behind the untheorisable passional commitments. The existentialist real interest is not in passional commitments, but to solve the problem of the relations with others and the extent of our participation in solving the problem. Rather than start from a general view of knowledge, human knowledge, whether scientific or rational were the product of shifting human desires rather than of a reality extrinsic to those desires. According to Richard A. Posner,

It is that they wished to shift attention from a passive, contemplative relation between an observing subject and an objective reality, whether natural or social, to an active, creative 
relation between striving human beings and the problems that beset them and that they seek to overcome. ${ }^{7}$

If the above quotation describes the possibility of a form of knowledge with a shifting nature and how human beings seek to overcome their problems, much still remains to be explained if we are to be motivated by an account of cultural other. The point of view of the cultural other is to see the extent to which the problem confronting mankind can be solved through multiple perspectives. There would be a further problem if all human knowers on the basis of a perspective to truth seek to overcome the problem (scepticism) the same way. The task of the cultural other is that we can do epistemology by multiple approaches in solving problems that beset human beings.

This is the point post-modernism seems to be making against modernism.

... modernism is seen as a phenomenon stressing rationalism ... which gives order to a reality that can be known through the appropriate, that is scientific method. It also stresses an optimistic faith in mankind's uniqueness and ability to progress. ... post-modernism, on the other hand, emphasizes the lack of foundation in knowledge. ${ }^{8}$

That such expectation, that is, knowledge lacking in a foundation can be met in postmodernism without limits on human aspiration for multiple perspectives is what has led Gene Edward Veith to state that the concluding task of existentialism is that it is "the philosophical basis of post-modernism"". If the epistemic goal defended in cultural other were not to endorse an already existing knowing modes or perspectives, Veith's point quite plausibly is an anticipation of a seemingly important insight of Kierkegaard. According to Kierkegaard, "my design here is not to teach the Method which everyone follow in order to promote the good conduct of Reason, but only to show in what manner I have endeavoured to conduct my own."10

As we have seen, certain accounts of knowledge, notably rationalism and empiricism have been theorised to the point of reducing both as the epistemic aspirations of mankind. The "emerging world view cast humankind in an observing mold. Through perception, measurement, and mathematics, the human mind would uncover the secrets of nature, including those of the mind itself, as part of nature." 11 Empirical knowledge or rational knowledge, both are not problematic for the existentialist, the real issue concerns the fact that all concepts of knowing should be graspable from these modes of knowing.

While avoiding the question of the relations with others, these knowing modes foreswear in the name of epistemic rational integrity 'forget' that that they ever had to make any passional commitment. ${ }^{12}$ One thing to say about epistemic rational integrity is that in spite of its distinctiveness and clarity, it focuses on truth to the extent of failing to elicit a strategy for bringing out the manner in which others have a claim to knowledge. Hayward has this to say:

In order to avoid confusing Dasein with one aspect of this complexity Heidegger focuses on Dasein in its most undifferentiated state, that is its everyday state. This helps 
clarify that which precedes, and makes possible, more definite mode of being such as theoretical thought. There is then the possibility of rethinking the troubled relation between everyday experience and theoretical thought. ${ }^{13}$

The problem with epistemic rational integrity is that it determines the forms in which scientific, rational or empirical knowledge-claims may be resisted in grasping how the others develop their accounts of knowing. As noted by Deleuze, Hume no longer feels that every modes of knowing will have similar peculiarities: we must distinguish between two kinds of reason, the reason that proceeds on the basis of certainty (intuition and demonstration) and the reason that proceeds in terms of probabilities (experimental reason, understanding). ${ }^{14}$

One important thing to say in making sense of the cultural other in the fabric of knowledge is that no one account of knowledge that has been developed can be said to be the best so far produced. This is because as remarked by Heidegger, every knowledge-claim has its force and time. For this reason, applied to culture, the 'known unknown' "both defines and makes us fearful." 15 What we hope to solve by incorporating culture into the fabric of knowledge is through our relations to others rejects feature of a whole judgement in accounting for knowledge.

By this, it is meant that despite the technological, economic and other advances that are features of our world, it is inevitable that our humanistic advancement must sooner or later rely on progress being made in the area of basic principles that relate to understanding each other and acknowledging the legitimacy of other ways of knowing, which may not necessarily be similar to, or consistent with, our own. ${ }^{16}$ Added to this is the fact that not all epistemic aspirations are tied and initiated in satisfying the ideals of certainty, immutability, indubitability by accentuating our obsessions in defeating scepticism.

\section{Points of View and Perspectives in Yoruba Account of Knowing}

At this juncture, the questions before us include: Is there any way to make sense of the cultural other within the Yoruba framework in a fashion to show that the destiny of knowing is not tied to the rational mode of knowing? In order to become a knower, does it mean one must be a rationalist or a scientist in the senses earlier discussed? Can we have a mode of knowing that is not essentially linked to the legacy of rational mode of knowing? To do justice to these questions, we will turn to the cultural view maintained by the Yoruba and indicate the extent to which it represents a paradigm not yet established or to which little is known because of the rational or scientific mode of knowing in which all modes of knowing seems to have been assimilated. In what follows, the basic concepts of truth, belief and knowing developed by the Yoruba will serve to loosen the grips of knowing by rationalism, empiricism or scientism. These modes of knowing are mere aspects of the multiplicity of the everyday, and thus, they should not be weighted as foundational. The Yoruba framework, as a cultural other must therefore reveal other modes of knowing as aspects of the everyday while it is not foundational to these other aspects, it must not be abandoned when confronted with these modes of knowing. Or, better still, it should not be substituted by other versions of knowing interpreted either as weaker or stronger. As we have seen, the basic strategy of the cultural 
other is to bring to the fore unsuccessful attempts of rationalism, empiricism or scientism as foundationalist frameworks by developing considerations for other modes of knowing.

This is adequately supported by Kola Abimbola who maintains clearly that "the hallmarks of Yoruba are to be found in a unique set of religio-philosophical beliefs on the basis of which the Yoruba organize, regulate and moderate their day-to-day lives." ${ }^{17}$ The traditional view of knowledge yields a familiar understanding that what is required to be added to a true-belief to become knowledge is justification. In what follows, as a main feature of contention, Gettier, however, has warned us that such epistemic achievement is not generalisable. Hence, the central task of the problem of knowledge is to arrive at a distinction between knowledge and belief.

The Yoruba relies on the resources of the cultural other in arriving at a demanding distinction between knowledge and belief. While knowledge is imo, belief is igbagbo. It is well to remember that discourse on culture typically employs language of nearest association. The most common philosophical source of the Yoruba example is the work of Barry Hallen and J.O. Sodipo: Knowledge, Belief and Witchcraft ${ }^{18}$ Both start by accepting the description of the nature of knowledge and belief given by the Onisegun. ${ }^{19}$ Here, we find the hint that two conditions must be satisfied for something to count as imo. A person mo (knows) a thing if he has seen or witness the thing by himself. This is more than remotely connected with sight, that is, $r i$. The distinction between seen ( $r i)$ a thing and know ( $m o$ ) it is not if we allow that it is only $r i$ that is allowed as an antecedent for mo. A correct understanding of the essential nature of our senses is a requirement for knowledge they induced. While we may acknowledge a general scepticism about our senses, more generally too, $r i$ (sight) is less controversial because of a structure of visual activism that accompanies its understanding.

Another way to view the place of $r i$ is that in accounting for imo, one is not absorbed by naïve realism where knowledge elicits a propositional attitude that everything is knowable whether perceived or unperceived. Knowledge thus depends on the cognitive functions of our faculties. The following are perceptual vocabularies. People take mo to be as adequately supported by one's evidence with respect to $r i$.

If you mo it (by touch), you have already mo (by sight) ... If I close my eyes and I touch ( $f i$ owokan) ... it is because I have mo by sight. ... If you had seen it before, and you touch it, you touch it in vain. ${ }^{20}$

Apart from firsthand knowledge, the Yoruba recognises the need for another variant of knowledge. As earlier hinted in this section of the work that knowledge needs not aspire to the ideal of certainty, the other variant of imo presupposes not necessarily indubitability in the Cartesian sense (because others are not involved), but rather explanation (alaye).

In this further aspect that concerns alaye, the emphasis is such that knowledge has significant influence on what matters to people in their everydayness. Its real importance rests on the fact that to know a thing is not restricted to logical relations that hold between propositions. When imo is "challenged," ${ }^{21}$ justification is obtained by explanation (alaye). Alaye becomes important when others seek to preserve the epistemic integrity of that which a person might have claimed to mo first hand. What a person mo should not leave others thinking 
that it is a guess. The principle behind alaye is that we do not blame the person that claims to know a thing first hand, but others who fail to seek for explanation before we have a shared view of the knowledge-claim.

The more willing a person that claims to know a thing is prepared to laye (explain), "the imo of one man can become the imo of another." 22 This concomitance and complementarist requirement that knowledge is justified by alaye impinges upon the conceptualisation of knowledge as presupposing propositional attitude. To the Yoruba, to mo (know) requires that we consider others in our knowledge-claims because they are presumably participants.

If participation is a precondition for knowing, the recognition is a basis for inferring, according to the Yoruba that omode gbon, agba gbon, la fid a Ile - Ife, that is, (wisdom of the young, wisdom of the old, is the basis for establishing Ile - Ife). ${ }^{23}$ We would never act on any epistemic claim except that it is sustained by the participation of everyone. Admittedly, it must be stressed that this feature of Yoruba epistemology provides a starting-point for African epistemology. According to Didier Kaphagawani and Jeanette Malherbe, traditionally speaking, the take-off premise should be "We are, therefore I am.",24

It follows from above that in claiming to know something, rationality requires emotion as an epistemic operator. Emotion becomes an epistemic operator so that we do not loose our concentration on the closure strategy which recognises and expects knowledge to be possible only in certain domain of existence. This much has been anticipated by Merleau - Ponty's view: you ought to perceive in me, not that I perceive, a fact which suffices of itself in destroying sensitivity to non-participatory guided lexicon. What is important here is the shift from the reliability of first person knowledge upon which epistemology has been based since Descartes. ${ }^{25}$

The scope of the Yoruba account of knowing will be under-described if this participatory requirement is not added. While exploring some basic connections between Yoruba epistemology and African epistemology, we discovered that with the Yoruba account, there can be exceptions to the general background to a standard picture of African epistemology as being authoritative. The epistemic goal of the Yoruba is to get beyond a concession that allows knowledge to be derived from a domain. Thus, one might wonder why "an emphasis on age as a necessary condition for knowledge and wisdom ... denies epistemological authority to the young and able."26

The two variants of knowing according to the Yoruba must yield ooto, which means truth. Anything that I mo is ooto. ${ }^{27}$ A pertinent question to ask is this: what if our account yields a falsehood? The attempt to answer this question will form a basis of comparing and distinguishing knowledge (imo) and belief (igbagbo). The sort of content the Yoruba attributes to belief (igbagbo) is different from that of knowledge which requires, for instance, that $r i$ (sight) should be incorporated especially in the first-hand account. The Yoruba interest is readily an appeal to hearing faculty for anything to be believed, that is, gbo. Gbo means to 'hear'. Gbo is central to belief because its natural limits far outweigh that of ri (sight) in firsthand knowledge-claim. The question of how distinction is drawn between knowledge and belief is based on the understanding that $g b o$ requires a different attitude since it is qualifiedly second hand. To throw shared light to what you gbo, we must remove constraints on $g b o$, by 
gba it (accept it).

Thus, we arrive at gbagbo by conjoining $g b a$ with $g b o$ "which is our primary interest." 28 The supreme benefit of incorporating $g b a$ is that one quite different pressure operates in having a belief - forming attitude. This is called iwa (character). What one believes cannot be foisted upon an ignorant public. The reason for incorporating $i w a$ is to repudiate every kind of psychology in Yoruba epistemology proven pejoratively as ohun ni kan lo gbo (he is the only person that hears it). While avoiding falsehood, the chief test of gbagbo is to relegate to the background the BIV challenge. BIV, simply means brains- in -vats. It is the sceptical challenge that defends the view that a belief in a non-participatory, external world is possible. It is a vigorous sceptical strategy which holds that what one believes is an inferential justification for what one does not believe. Denial and affirmation does not constitute a diametrical opposite. Both are unitary. As a sceptical challenge, it wields grip over any account of knowledge beyond every anticipation; for justification for what one knows is compatible with a sleight of non-worldliness. The spread of its illustrations leave open the question of participation by others, even when there is tension cast over personal involvements. Its reinforcement in a cultural setting deserves a sweeping diagnosis of the "known unknown" as a target category of a diametrical opposite. Although, it is absent in the knowing orientation of the Yoruba, a move towards getting out of it as a basis of expectations for both antecedent and consequent justification of our beliefs will be a welcome relief. The Yoruba account of knowing is biased in favour of participation over non-Cartesian presuppositions, where participation is the view that what justifies an account of knowledge is a shared-world which allows a makeup for both antecedent and consequent justification of beliefs. That the Yoruba is disposed towards this priority is pretty widely delineated as follows. While ooto (truth) is needed, the Yoruba do not brush aside falsehood as the choice between the two can only be eliminated by familiarity with that person's iwa (character) upon which we hope to form our belief. Belief in this context is an intentional concept directed at $i w a$. Belief should improve our grasp of the speaker - hearer relationship. This sort of relationship is captured by Hallen and Sodipo as follows:

Hearing and Agreeing: this would represent successful communication, in that the hearer (in a speaker - hearer relationship) feels he understands what is being said and accepts it - with the status of gbagbo - as part of his own store of information. ${ }^{29}$

In conclusion, the Yoruba knowing paradigm springs from the way they are involved, the way they encounter their world and the way they encounter the others. The Yoruba seeks a truth that cannot be divorced from the complexity of human experience. While not disputing the intentionality of average truth, the Yoruba account has implications for average truth as epistemic priority in dealing with issues.

\section{The Paradox of Average Knowing and Knowing from the Standpoint of Ifa}

As pointed out initially, our primary interest is to explicate the primacy of knowing within a cultural framework. This carries us a stage further in our indifference to imitation of standards and paradigms of knowing as epistemic goals. What one does to acquire this perspective is to bring knowing into confrontation with the accomplishments of that culture 
regarding knowing, as well as making the accomplishments intelligible, even, while this might not be one's interest.

The expression, knowing is often used with an average understanding. As commonly understood, what, then, does the averageness belonging to knowing mean? Averageness presupposes that knowledge must be delineated as confrontation with the interpretation of social bond. It simply means the compulsion to share and derive knowledge from others whether personal or impersonal. It is this sharing and derivation that help create a social bond. Knowing, laden and charged as it were with averageness serves the interest of a cultural order when all ideas about knowledge are knitted into a full theme of social bond.

The problem is to explicate or say what this social bond is. Here, one will be compelled to have recourse to Heidegger for the tremendous influence he wielded in the task of developing strategies for avoiding the commonplace objections to personal achievements, be it knowing, without requiring the others, especially the community. Heidegger made an important distinction between what he calls "mine-ness basis for inauthentic and authentic self-understanding." "30 Heidegger seems to hold that rootedness of individual epistemic achievement often desired, but a recast of mine-ness as a proper object of theorizing is still in principle fortified by another framework in which mine-ness could be revised not to mean "it is occupied with its own capacity." 31 It is "'in each case mine." 32 For Heidegger, mine-ness as basis for authentic self- understanding constitutes the most appealing for a grip on the cultural order while mine-ness with the rendering "in each case mine" rests on a mistaken assumption which denies knowing as a language of inter subjectivity requiring a social bond with both the personal and the impersonal.

Amazingly, there are better ways to avoid mine-ness as basis for inauthentic self-understanding. Which of the mine-ness is better is determined by how it help us to attain the goal of cultural order which is the notion of social bond as discursive in order to formulate the nature and meaning of knowing. Without leaving a gap between knowing and the social bond, here is how the Yoruba view mine-ness inauthentic account of knowing attesting to the likelihood that the hypothetical knower has achieved epistemic loss as knowing is made to bear inauthentic weight. Ogbon amoju a ma pa ologbon lara. This translates to: Undue quantification of knowledge is inimical to its possessor. The thrust of this Yoruba saying is that the knower must receive the delightful in the quest to know rather than the harmful. Thus we must say that the above Yoruba saying poses challenge to the account of knowledge as a specialized endeavor which builds on the epistemic achievements of an individual knower. Evidently, an individual must be prepared to embrace the maxim of average knowing, "the individual and the community are one". This is why, Heidegger, in spite of his belonging to the existentialist, still disapproves knowing subjectively without requiring public interpretation as an immediate layer of intentionality, construed as directness.

In this sense, if individual knowing as pertains to this contextual consideration is threatened on account of "want of bond" with the community the individual should be anxious to avoid the suspicion of amoja, that is, an expression, emphasizing the negative aspect of an individual's epistemic integrity when what he claims to know is spectacularly wrong. Much as the Yoruba is not contented with the defective acquaintance with the solipstical achievement of an individual in regard to knowing, a first rank conception of 
knowing is average which teaches that variety of individual's epistemic achievements are false, as a number of them are traceable to uninvestigated intuition.

For an indication of the ill consequences of imparting the entirety of one's individuality on the quest to know, let us turn to Ifa, among the Yoruba whose consultancy need not be fatal to sufficiency about intuitive belief. There are many accounts of Ifa, however, we are inclined to its characterisation as "presentation of one's aspect of Yoruba culture, in respect to knowing." ${ }^{33}$ With this claim concerning the tenor of Ifa, we must submit to the optimism of Wande Abimbola that there is "the need for every person to consult Orunmila from time to time." ${ }^{34}$ Orunmila is another name for Ifa, though an individual whom is reputed to have turned out the mass of compilation to be frequented and consulted in terms of knowing, thereby ensuring a secured footing for Yoruba as a paradigm of cultural order.

It is an ideal to aim at intuition, but in most cases, it is unattainable. Let us see how Ifa could be a valid check on intuition, thus, exhibiting another dimension of average knowing. An impulse is given to it by Wande Abimbola in a passage he quoted from Ifa Corpus.

Ori buruku ki wu tuulu

Aki da ese asiwereee mo loju-ona

A ki mo ori oloye lawujo

A dia fun Mobowu

Ti I se obinrin ogun

Ori ti o joba lola,

Enikan o mo

Ki toko-taya o mo pe'raa won ni were mo

Ori ti o joba lola

Enikan o mo. ${ }^{35}$

A bad head does not swell up.

Nobody knows the foot-prints of

A mad man on the road.

Nobody can distinguish the head destined

To wear a crown in an assembly.

Ifa divination was performed for Mobowu

Who was the wife of Ogun.

The head that will reign tomorrow, Nobody knows it.

Let husband and wife stop calling

Each other names.

The head that will reign tomorrow, Nobody knows it. ${ }^{36}$

One interesting point at this juncture is that if we can be said to believe our knowledge-claims regarding intuitive appeal, why will one not be able to doubt them 
as intuition regarding our aesthetic grips on one's Ori [Head] does not count on just what determines success. The Ifa passage cited above suffices for the invalidation of intuition as a prevalent superstition that an individual may owe to his personal existence.

A timeless feature of a culture is retention and transmission. Among the Yoruba, knowledge-claim is secured by bringing it into confrontation with a theme or fundamental experience by emphasizing sharing and consultation as the basis for allknowing activities by putting them on a cultural footing. Thus, a recognition of the common ground shared by the problems of the explication of individuality and the explication of averageness proves the falsity of the entire dominance of intuitive appeal as a factor to take into account in knowing.

The example of intuition is meant to show how its reliance can involve a flux of experience we may nevertheless be in constant intuitive touch with. This suggests that Ifa's consultancy as a fabric of knowing is far removed from how we ordinarily understand knowing. For those who are inclined to update their understanding, whatever we may hold as to the ontology of Ifa, it provides important way in which the edifice of knowing fits into a template for defeating pseudo-problems in the search for truth.

In emphasizing the various aspects and dimensions of average knowing, Ifa is a broad strategy that is articulated along certain essential dimensions and therefore come close to a clarified status. For knowing achievements to be possible, these dimensions put Ifa in a settings that takes the intentional descriptions of the methodological template of academic disciplines as precondition for knowing. Knowing is approached from the presupposition of dialogic, and in stressing this dialogical reading of Ifa shows that knowing is average from the start. Thus, in asking: what is knowing? means a disengagement from individualistic category exhibited by detachment. On the basis of such disengagement, the following is intended:

a. What is the statement of the problem and what is it about? Ifa introduces an indicative dimension whereby subject-matter remains a core knowing commitment. Hence, the subject-matter is often the case, the fundamental concern that motivates the quest for knowing. This may include: success, marriage, wealth, illness, conflict, the future and the past.

Along this path, knowing is a kind of dialectical imperative whereby knowledge depends on the interaction between how the unsophisticated individual views knowing apart from the involvements of Ifa and the explanations if Ifa, often expressible in poem, rather than in propositions. The states of arousal in the individual which may include cause of illness, barrenness or misfortune is pushed a bit the dialectical imperative that Ifa has a yet higher role in the explanation of these bits of arousal. According to Kola Abimbola,

Ifa divination is one important means of diagnosis......the priest establishes a link between the Client........, in a series 
of steps. After a series of invocations, the priest divines to determine the

$\underline{\text { Odu }}$ [i.e, book] of the Ifa literary

Corpus from which to select a poem. ${ }^{37}$

From above, the importance of Odu [i.e. book] provides a possibility for further involvements of other priests which might pave the way for further explanations, illuminations and clarity on the statement of the problem.

On this point, while the individual can be recognized as a category in regard to the arousal of the statement of the problem, which presupposes explanation, knowledge cannot be reduced to the individual. Much depends on what counts in the conception of a problem and its therapy. The necessary consequence of therapy and explanation from Ifa undermines the status of epistemic realism from which knowing is a substitution and replacement by the absolute category of certainty, so far as the initial epistemic status of the problem in question remains unaffected. Averageness, is thus required when the practice of giving and getting knowledge forecloses any effort at some sort of either absolutist or subjectivist reduction of knowledge-claims. What needs to be entrenched in any cultural practice regarding knowledge is averageness. This stands in opposition to the absolute category of certainty in traditional epistemology where the knower cannot question further beyond the direction indicated by a simple showing of solipsism. Knowing, construed as contingent upon Ifa has averageness intended, rather than either the subjectivist or absolutist.

b. What is its thesis and the kind of effect it has on the individual.

This point stresses the average character of knowing. In attempting to illuminate the distinctive priority of Ifa, it requires everyday interpretation. Ifa is inseparably intermixed with everydayness, as the Yoruba will urge that, bi eni se ri, ola ko ri be ti ofi babalawo ndifa ojojumo. Tomorrow may not resemble today which forces a diviner to consult Ifa everyday. This is more than a tentative conclusion that what the Yoruba wants to depose is the absolutist category of knowing. Everydayness interpretation by Ifa can create divergent moods ranging from spirit of sacrifice to patience and the like. The thesis is that only good character unites the individual with Olodumare (the Omniscient).

\section{Conclusion}

By way of conclusion, we must make some clarifications such that the Yoruba account of knowing can be put on a more cultural footing. Ifa is personified as a consultant, with the additional character of a divinity likened to an omniscient. Specifying knowing in terms of everyday clarifications and average involvements requiring consultation is not the problem, but the real problem consists in how to locate the true epistemic need, not the desire of the individual. These points simply show that the scope and target of both everyday analysis and average conceptions of knowing 
differ. In formulating an account of knowing, we end up getting different notions. The Yoruba overall cultural scene, however, admits that knowing requires that the individuals should pay attention to the post-every day and post-averageness by developing a theme that is uninfected by the vagaries of everydayness and averageness. Iwa (that is, that which endures, or character.) Its distinctive priority among the Yoruba indicates the importance of not leaving open what becomes of knowledge when it is presumed to be acquired.

The Yoruba is deeply influenced by Iwa, because anything an individual mo [know], must be otito [that which lasts and endures in time]. Iwa is not only a search, but represents a standard of well-being in knowledge, which is the only ground the individual can be united with the omniscient. When the individual is united with the omniscient, all that one might have acquired in the quests for knowing becomes an unnecessary appendage. An Ifa poem quoted by Rowland Abiodun has this viewpoint in mind:

\author{
Iwa, Iwa la n wa o Iwa \\ Ire gbogbo ta a ni \\ Ta a niwa \\ Ire onire ni \\ Iwa, Iwa la n wa o Iwa.
}

Iwa, Iwa is what we are looking for

All the good things of life which a man has,

If he lacks good character

They belong to someone else

Iwa, Iwa, is what we are searching for. ${ }^{38}$

The important ending to this is that, knowing should not be viewed in the contexts of either everyday analysis or average conception, but a fruitful specification of one's epistemic aspiration. Thus, as an example of a cultural other, the Yoruba is exemplary.

\title{
References
}

1. Abimbola, Kola. 2006. Yoruba culture, a philosophical account. United Kingdom: Iroko Academic Publishers. Pp. 99-100

2. Deleuze, G. 1989. Empiricism and subjectivity an essay on hume's theory of human nature. New York: Columbia University Press. p. 28.

3. Deleuze, G. 1989. Empiricism and subjectivity an essay on hume's theory of human nature. New York: Columbia University Press. p. 127

4. Sanderson, G. 2004. Existentialism, Globalisation and the Cultural Other in International educational journal. http://iej.cjb.net. p. 2. 
5. Sanderson, G. 2004. Existentialism, Globalisation and the Cultural Other in International educational journal. http://iej.cjb.net. p. 1.

6. Sartre, J.P. 1961. Problem of method. London: Hutchinson. p. 11.

7. Posner, R.A. 2003. What has Pragmatism to offer Law? Philosophy of law and legal theory. Dennis Patterson Ed. Blackwell Publishing. p. 181

8. Lang, C. 2008. http://www.brocku.ca/english/courses/4F70/index.php Last updated on August 4, 2008. p. 1

9. Veith, G.E. 1994. Postmodern times. Crossway Paperback. p. 38.

10. Kierkegaard, S. 1843. Fear and trembling. Penguin. p. 42

11. Posner, R.A. 2003. What has Pragmatism to offer Law? Philosophy of law and legal theory. Dennis Patterson Ed. Blackwell Publishing. p. 181

12. Bishop, J. 2007. Believing by faith an essay in the epistemology and ethics of religious belief. Clarendon Press. p. 222.

13. Hayward, R.J. 2002 Theory and the everyday in martin heidegger being and time. www.dooy.salford.ac.uk/ext/hdg.rh.html. p. 3.

14. Deleuze, G. 1989. Empiricism and subjectivity an essay on hume's theory of human nature. New York: Columbia University Press. p. 65.

15. Sanderson, G. 2004. Existentialism, Globalisation and the Cultural Other in International educational journal. http://iej.cjb.net. p 11

16. Sanderson, G. 2004. Existentialism, Globalisation and the Cultural Other in International educational journal. http://iej.cjb.net. Pp. 1-2.

17. Abimbola, K. 2006. Yoruba culture a philosophical account. United Kingdom: Iroko Academic Publishers. p. 25.

18. Hallen, B. and Sodipo, J.O. 1986. Knowledge, belief and witchcraft. London: Ethnographical.

19. These authors tend towards the Onisegun because there is no vantage point from which to extract knowledge except from the elders and herbalists who are well grounded.

20. Hallen, B. and Sodipo, J.O. 1986. Knowledge, belief and witchcraft. London: Ethnographical. p. 61.

21. Hallen, B. and Sodipo, J.O. 1986. Knowledge, belief and witchcraft. London: Ethnographical. p. 63

22. Hallen, B. and Sodipo, J.O. 1986. Knowledge, belief and witchcraft. London: Ethnographical. p. 63

23. Ile-Ife is believed to be the cradle of civilisation and all there is for the Yoruba. The issue here is that its ontology is not one-sidedly reached.

24. Kaphagawani K. and Malherbe, J. 2002. Epistemology and the Tradition in Africa. The african philosophy reader. Coetze P.H. and Roux, A.P.J. Eds. South Africa: Oxford University Press. p. 306. 
25. Davidson, D. 2004. Problems of rationality. Oxford: Clarendon Press. p. 18.

26. Kaphagawani K. and Malherbe, J. 2002. Epistemology and the Tradition in Africa. The african philosophy reader. Coetze P.H. and Roux, A.P.J. Eds. South Africa: Oxford University Press. p. 266.

27. Hallen, B. and Sodipo, J.O. 1986. Knowledge, belief and witchcraft. London: Ethnographical. p. 62.

28. Hallen, B. and Sodipo, J.O. 1986. Knowledge, belief and witchcraft. London: Ethnographical. p. 64

29. Hallen, B. and Sodipo, J.O. 1986. Knowledge, belief and witchcraft. London: Ethnographical. p. 64

30. Heidegger, Martin.1988. The basic problems of phenomenology. Trans. Albert Hofstadter. Bloomington \& Indianapolis: Indiana University press. p . 170

31. Heidegger, Martin.1988. The basic problems of phenomenology. Trans. Albert Hofstadter. Bloomington \& Indianapolis: Indiana University press. p . 170

32. Heidegger, Martin.1988. The basic problems of phenomenology. Trans. Albert Hofstadter. Bloomington \& Indianapolis: Indiana University press. p . 170

33. Emmanuel, Abosede. 2000. Ifa festival. Lagos: West African Book Publishers Limited. p .53. emphasis added.

34. Abimbola, Wande. 1976. IFA: an exposition of ifa literary corpus. Ibadan: Oxford University Press. p .147.

35. Abimbola, Wande. 1976. IFA: an exposition of ifa literary corpus. Ibadan: Oxford University Press. p .147.

36. Abimbola, Wande. 1976. IFA: an exposition of ifa literary corpus. Ibadan: Oxford University Press. p .147.

37. Abimbola, Kola. 2006. Yoruba culture, a philosophical account. United Kingdom: Iroko Academic Publishers. p. 80

38. Abiodun, Rowland. 1983." Identity and the artistic process in Yoruba aesthetic concept of Iwa." Journal of culture and ideas. Ile-ife: Alada Study Circle of Nigeria. p.17 